\title{
The Impact of Body Image and Self-Esteem on Turkish Adolescents' Subjective Well-Being*
}

\author{
Firdevs Savi-Çakar \\ Mehmet Akif Ersoy University, Burdur, Turkey
}

\author{
Sevil Savi-Karayol \\ Balance CiC, Surrey, England
}

\begin{abstract}
The aim of this study is to determine impact of adolescents' self-esteem and body image on subjective well-being. In this study, the structural model are tested. Study group of the research consist of 164 students 90 females and 74 males. Self-esteem scale, body image scale and subjective well-being scale are in collection of data for the study. It is determined that the theoretical model built on the fact that adolescents' self-esteem and body image have influence on their subjective well-beings was verified with structural equality model. These results demonstrate that self-esteem and body image perception affects the sense of subjective well-being positively. Both variables explain $28 \%$ of the change in subjective well-being feeling. There are significant differences according to gender adolescents' self-esteem and body image, but there are not significant differences according to gender their subjective well-being. Based on this, it may be affective to focus on adolescents' subjective well-being in psychological and guidance studies especially in schools and to implement psycho-education programs towards increasing adolescents' well-being.
\end{abstract}

Keywords: adolescence, self-esteem, body image, subjective well-being

\section{Introduction}

According to Erikson (1968), adolescence is a very important phase in the development process as in the life span of a human for the development of the self. In this period, the adolescent gradually separates himself/herself from the family both socially and emotionally as well as economically and mentally; he/she may also develop different tastes and attitudes, as he/she begins to find his/her own way in the world. For the adolescent, the optimal time for achieving a sense of identity is during adolescence, and adolescent describes sense of identity as a feeling of being at home in one's body, a sense of knowing where one is going and an inner assurance of anticipated recognition from those who count.

In the literature, subjective well-being of adolescents is examined in terms of some variables and it is emphasized that subjective well-being has contributions to adolescents' development and mental health. Raising happy, healthy and moral children is the ultimate goal, not only of all parents but also of all societies. If adolescents are encouraged to become morally strong and reasonable at a young age, they develop into sensible and respectable adults (Park, 2004). Adolescent well-being is a relatively broad concept referring to a good or satisfactory condition of existence. A state characterized by health, happiness, and prosperity. It refers to the

\footnotetext{
* This paper is presented in The Third European Conference on the Social Sciences, July9-12, 2015, England. Firdevs Savi-Çakar, Asst. Prof., Mehmet Akif Ersoy University. Sevil Savi-Karayol, Mental Health Specialist, Balance CiC.
} 
functioning of an adolescent at a high level of behavioural and emotional adjustment and adaptiveness and not merely an absence of illness (Reber \& Reber, 2001).

Subjective well-being is not only subjective since it contains evaluations of the individual, but also a general evaluation of all aspects of life that covers positive measurements of an individual regarding his/her own life and self. There are three important sub-dimensions of subjective well-being. These include: positive affectivity: emotions such as pride, confidence, enthusiasm, interest and joy; negative affectivity dimension: anger, hatred, guilt, feelings like sadness and a third dimension: namely, life satisfaction dimension, subjective well-cognitive components; and individuals' assessment of life satisfaction in various areas of life (Deiner, 1984; Myers \& Deiner, 1995).

Subjective well-being is one of the concepts examined by several theories. Among these theories, according to the Wellness Circle Model, subjective well-being is related to maintaining lifetime well-being state and prevention of elements with risky potential, and it consists of characteristics of healthy person (Korkut, 2004). Well-being means living a life which is functional in all field socially, personally and ecologically with the objective of orienting towards optimal level of health, with integration of body, mind and soul, and with the objective of living more meaningful life bearing personal goals (Myers, 2001). Connection models tries to explain people's tendency to be happy and deals with subjective well-being under the light of cognitive principles. In the cognitive approach based on an individual's attribution to personal events, if good events are attributed to cognitive elements, then happiness will rise (Schwarz \& Clore, 1983). According to the judicial theory, an individual's level of subjective well-being is associated with the results of his comparison between a set of standards with real conditions. If the actual situation is over the criteria, happiness will occur (Diener, 1984). In social comparison approach, however, individual tends to compare himself/herself with other individuals and evaluates satisfaction and happiness. If the individual considers himself/herself better than others, his/her happiness and satisfaction increase. If individual considers himself/herself worse than others, individual becomes unhappy (Diener, Suh, Lucas, \& Smith, 1999).

Columbo's (1986) conceptualization of adolescent well-being describes wellbeing as a multidimensional construct, incorporating psychological, physical, and social dimensions. According to Bar-On (1998), the most important components of adolescent psychological well-being are self regard, interpersonal relationships, independence, problem-solving, assertiveness, reality testing, stress tolerance, self-actualization and happiness. Adolescents' subjective well-being is especially important in terms of healthiness, it is indicated that people with high emotional stability and social participation have higher subjective well-being (Gerrig \& Zimbardo, 2010). Adolescents with higher than average psychological well-being are regarded as more successful in meeting situational demands and stressors while a deficit in psychological well-being can mean a lack of success and the occurrence of emotional problems (Visser \& Routledge, 2007). Therefore, while identifying the factors that influence adolescents' subjective well-being contributes to psychological development of adolescents, establishment of self-integrity and being in a better level (Ryan \& Deci, 2000); high level of subjective well-being among adolescents is considered as a way for them to withdraw from negative outcomes and to experience a positive development stage (Diener, 1984; Diener \& Seligman, 2002). For Park (2004), subjective well-being is multidimensional and many different factors interact to determine the well-being of individuals. These factors include: personal and environmental stressors and resources, coping styles as well as demographic variables such as race, gender and socio-economic class. It is important that adolescent subjective well-being should be understand to promote adolescence development. 
Self-perception is an individual's perceptions of his/her own self and how individual sees himself/herself (Özoğlu, 1975). The self-concept is dynamic mental structure and includes many components. These are: our beliefs related to memories of our own, our character traits, our motives, our values and skills; our most ideal self; our possible selves we want most; our positive or negative assessment of our own (self-respect); our beliefs about what others think about us (Chen, Boucher, \& Tapias, 2006). Self-esteem, on the other hand, is a concept related to an individual's sense of being valuable and important about himself/herself or self-love, self-reward, self-approval and considering himself/herself valuable. Self-esteem is defined as the emotional dimension of self. Along with ideas related who an individual is, it is also emphasized that individual has certain emotions and self-esteem is determined as the level of an individual's admiration of self and finding valuable (Adams, 1980). People's ideas related to self-esteem affect strongly their psychological state and other behaviors (Swann, Chang-Schneider, \& McClarty, 2007). Since concepts of self-esteem and subjective well-being consist of an individual's subjective evaluations related to himself/herself, some researchers indicate that self-esteem and subjective well-being are similar concepts (Lyubomirsky, Tkach, \& Dimatteo, 2006).

The concept of self-esteem appears to have three meanings in general. These meanings are self-love, self-acceptance and competence (Wells \& Marwell, 1976). An individual's self-perceived competence and feeling of worthiness create a basis for self-esteem. Self-esteem established as a result of these emotions is a significant determinant of an individual's perspective towards both himself/herself and outside world and individual's behaviors. Therefore, a person's self-esteem level as lower or higher directly affects his/her life (Akın, Baykara, Miral, \& Özakbaş, 1992). According to Walz (1992), healthy level of self-worth serves a social vaccination; self-worth is said to function as a protector and buffer against stress and other negative emotions. High self-esteem is closely associated with optimism and less anxiety (Kaplan, 1995); life satisfaction, functional behaviors (Guindon, 2002); mental well-being (Witmer \& Sweeney, 1992) coping behaviors (Jorgenson \& Dusek, 1990). People with high self-esteem tend to perceive themselves as worthy of respect and acceptance, as significant and useful people (Dönmez, 1985). In addition, while people with high self-esteem feel good about themselves, people with low self-esteem feel negative emotions more (Leary, Tambor, Terdal, \& Downs, 1995).

A mental picture of individual's body image is related to visible part of self, especially "physical appearance" self-perception specified as the symbol of self during adolescence (Adams, 1980; Collins \& Steinberg, 2006). Body image is defined as an individual's emotions about his/her own body. Identification and assessment method related to individual's body image come forefront more than others. The objective of acceptance of body image is for an individual to develop a realistic perspective towards his/her own body and to ensure happiness with such perspective (Akın et al., 1992). The most important change during adolescence is the change in physical appearance. Physical appearance, physical experiences and changes in sensation deteriorate the physical image. Body image is related to charm, balance, and gender role. At the same time, body image is a tool for assessment by peer group in terms physical force, physical sexual maturity and charm. Adolescents experience confusion of body image and internal self-image (Çelen, 2007).

Body image establishes an important aspect of self-esteem and mental health all throughout life (Harter, 1990). Among causes related to body perception among adolescents; it is emphasized that culturally proposed models have an effect; besides, family and peer pressure plays an important role; effect of adolescents' comparing themselves with their peers and their irrational thoughts about their bodies on (Lyddon \& Slaton, 2002). Body image has significant effects on self-acceptance, social self-confidence, popularity in opposite sex 
and athletic abilities (Canpolat, Örsel, Akdemir, \& Özbay, 2003). Negativeness in body image may cause decrease in self-esteem (Akın et al., 1992). Besides, a mismatch between the ideal and perceived body image is associated with dissatisfaction about body image and self-esteem among adolescents (Pesa, Syre, \& Jones, 2000).

Subjective well-being is associated with self-esteem (Deiner \& Deiner, 1995), optimism (Lucas, Deiner, \& Suh, 1996), personality traits (Myers \& Deiner, 1995); and it was found that people with higher levels of subjective well-being tended to have higher self-competence (Tong \& Song, 2004). At the same time, the high subjective well-being among adolescents in schools have a positive effect in terms of providing more academic participation, being more willing towards the subject to learned and sparing more time to study (Schaufeli, Martínez, Marques-Pinto, Salanova, \& Bakker, 2002). Adolescents with high levels of subjective well-being developed fewer externalizing problems in the wake of stressful events than did those with low levels of subjective well-being. This suggests that subjective well-being functions as a buffer against life stressors (Park, 2004). In this respect, while trying to keep adolescents' subjective well-being levels contribute to protection of their mental health (Gilman \& Huebner, 2006). Adolescent subjective well-being should therefore be studied in order to understand the factors. These factors mitigate the negative effects of stressful life events and work against the development of psychological and behavioural problems (Rask, Astedt-Kurki, \& Laippala, 2002).

In this study, a structural model was developed regarding the impact of adolescents' self-esteem and body image on their subjective well-being and it was tested with structural equaling model. It is considered that this study will contribute to researchers and studies towards multi-factored evaluations of subjective well-being in samples with similar cultural and social structure features and towards adolescents attending in first grades mainly in Turkey accordingly.

\section{Purpose of the Study}

The aim of this study is to determine impact of adolescents' self-esteem and body image on subjective well-being. In accordance with this objective, hypotheses of the research is as follows:

H1: Self-Esteem variable has a significant effect on the subjective well-being.

$\mathrm{H} 2$ : Body image variable has a significant effect on the subjective well-being.

H3: Self-esteem and body image variables together can explain variation on adolescents' subjective well-being.

\section{Methodology}

In this section, information about research model, population and sampling, data collection tools, data collection and statistical analysis of the data obtained are included.

\section{Research Design}

This study is a quantitative research in survey model and the structural model developed regarding the impact of adolescents' self-esteem and body image on their subjective well-being are tested with structural equaling model. Independent variables of the study are determined as body image perception and self-esteem and dependent variable is determined as subjective well-being. As seen, structural model of the research (see Figure 1).

\section{Participants}

Research data were obtained from 164 adolescents who were attending the first grade of university and accepted to voluntarily participate in the research. Gender distribution for adolescents was acquired from 164 
students $90(54.87 \%)$ of whom were females and $74(45.12 \%)$ of whom were males. The distribution of the students as per departments is as follows: 45 (27.4\%) students from Psychological Counseling and Guidance, 47 (28.6\%) students from Pre-School Education, 38 (23.2\%) students from Science Education, 34 (20.7\%) students from Classroom Teacher Department. Students' age range was determined as 18-21 ( $X=19.3)$.

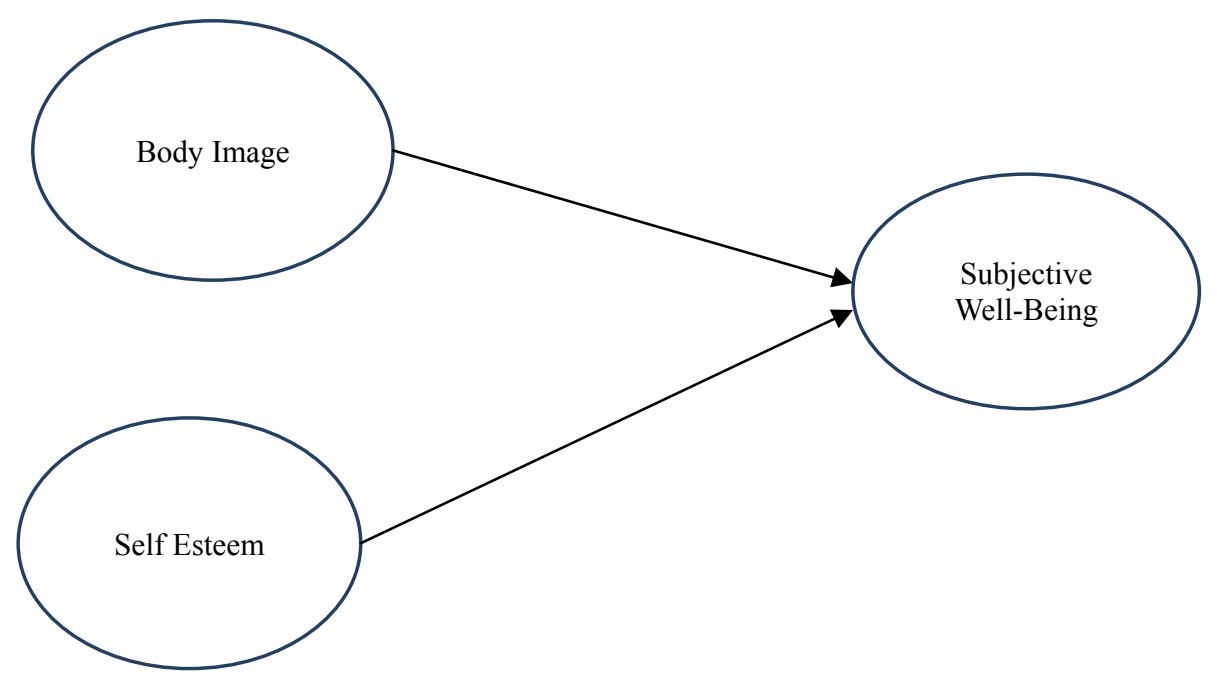

Figure 1. Structural model of the research.

\section{Data Collection Instruments and Data Collection}

Self-perception profile for adolescents. Sub-dimensions the scale developed by Harter (1988) obtained from the reliability study conducted in USA are as follows: Academic Ability, Social Competence, Athletic Competence, Physical Appearance, Close Friendship, Romantic Appeal, Job Competence, Creativity, Relationship with Parents, Humor, Morality, Intellectual and Global Self-Worth. Adaptation into Turkish culture was conducted by Şahin and Güvenç (1996) and it was revealed that internal consistency coefficients of the subscales varied from 0.77 to 0.90 , internal consistency coefficient of the whole scale was 0.88 . It is stated that holistic eigenvalue can be used as an indicator of self-esteem. Sample article: "Some young people are fairly at peace with themselves, however, some of them are not at peace with themselves mostly". Participants are demanded to select the sentence best expressing themselves among two sentences which include two alternative judgments and are separated with "but" conjunction, then they are demanded to select one option among "Completely Suits Me", "Partly Suits Me". High score obtained from this scale shows high perceived self-esteem (Şahin \& Güvenç, 1996).

Body-Cathexis Scale (BCS). developed by Secard and Jurard in 1953, is a scale that determines a person's satisfaction from 40 different body parts or their functions. Form of the scale used in our country is a measurement tool of five-point Likert-type consisting of 40 items ( 1 = "I like very much" -5 = "I do not like"). The most positive expression receives 1 point, and the most negative statement receives 5 points. According to this, the lowest score that can be achieved in the scale is 40 , the highest score is 200 . Level of received score shows the height of satisfaction level. The cut-off score of the scale is 135, those with scores below 135 are defined as the group of low body image perception. Increase in total score obtained from the scale indicates a decline in a person's satisfaction from his/her body or body parts and lower scores indicate an increased satisfaction. In the reliability study, two half-reliability of the test was obtained as $r=0.81$ for body satisfaction and as $r=0.90$ for the self. In adaptation study of the scale for university students in our country, two-half 
reliability was determined as 0.75 , item test correlations were determined as $r=0.45$ and $r=0.89$, and Cronbach's alpha coefficient was found as $r=0.91$ (Hovardaoğlu, 1992).

Subjective well-being scale-high school form. it was developed to assess subjective well-being of adolescents. In this 5-Point Likert type scale, 22 of items are positive and 15 of them are negative 37 items consisting and personal judgments on fields affecting life satisfaction. High point achieved from the scale shows high subjective well-being and low point shows lower low subjective well-being. Scale's Cronbach Alpha reliability coefficient was found to be 0.91 ; Pearson moments product correlation coefficient calculated as a result of test-retest implementation was found to be 0.45 (Özen, 2005). Comparing factor structure of the form prepared by Özen (2005) and Tuzgöl-Dost (2005) for college students, adaptation coefficient was observed as 0.85 . Within the scope of this study, the scale's Cronbach Alpha reliability coefficient is calculated as 0.88 .

Demographic Information Sheet. For the purpose of research objectives, this form was developed by the researcher to determine socio-demographic characteristics of participants.

\section{Data Analysis}

SPSS 15.0 Lisrel 8.51 software was used for data analysis. In advance of the Confirmatory Factor Analysis, the normal distribution conditions of variables (skewness and kurtosis) were analyzed and variables non-conforming to normal distribution condition (Log, Square Root) were included in the analysis. As for rating the model compatibility in confirmatory factor analysis and structural equation model, fit indices were classified as fit indices based on residuals, independent model, root mean square error of approximation (RMSEA), data criterion, and those based on relation criteria (Bayram, 2010). While analyzing model fits, $X^{2} /$ sd was discussed together with fit indices based on residual (SRMR, GFI), fit indices based on independent model (NFI, NNFI, CFI) and root mean square error of approximation (RMSEA). Acceptability of fit indices and best fit values are as follows (see Table 1).

Table 1

Fit Indices

\begin{tabular}{lll}
\hline Model Fit Indices & Acceptable Fit Values & Good/Best Fit Values \\
\hline$X^{2} / s d$ & $0<X^{2} / s d<5$ & $0<X^{2} / s d<3$ \\
RMSEA & $0.00 \leq \mathrm{RMSEA} \leq 0.08$ & $0.00 \leq \mathrm{RMSEA} \leq 0.05$ \\
SRMR & $0.00 \leq \mathrm{SRMR} \leq 0.08$ & $0.00 \leq \mathrm{SRMR} \leq 0.05$ \\
GFI & $0.90 \leq \mathrm{GFI} \leq 1.0$ & $0.95 \leq \mathrm{GFI} \leq 1.0$ \\
AGFI & $0.85 \leq \mathrm{AGFI} \leq 1.0$ & $0.90 \leq \mathrm{AGFI} \leq 1.0$ \\
NFI & $0.90 \leq \mathrm{NFI} \leq 1.0$ & $0.95 \leq \mathrm{NFI} \leq 1.0$ \\
NNFI & $0.90 \leq \mathrm{NNFI} \leq 1.0$ & $0.95 \leq \mathrm{NNFI} \leq 1.0$ \\
CFI & $0.90 \leq \mathrm{CFI} \leq 1.0$ & $0.95 \leq \mathrm{CFI} \leq 1.0$ \\
\hline
\end{tabular}

Note. Reference: Bayram, 2010.

In path analysis application in which confirmatory factor analysis and hypotheses are tested, it is required that all indicators have high factor loads in related factor ( $\lambda \mathrm{x}$ lambda), that $t$-values showing statistical significance of individual parameter predictions are significant and that error variances are high (Çokluk, Şekercioğlu, \& Büyüköztürk, 2010). 


\section{Results}

\section{The Resuls of Descriptive Statistics}

The findings of the research are given in the following order: related to dependent and independent variables of the research are included; and confirmatory factor analysis results related to the measurement model and finally, findings related to hypothesis of the research are included.

In Table 2, Range, Minimum score, Maximum score, Mean, Standard Error and Standard Deviation values obtained by adolescents from self-esteem scale, body image scale and subjective well-being scale are given.

Table 2

Descriptive Statistics

\begin{tabular}{lcccccc}
\hline & Range & $\begin{array}{l}\text { Minimum } \\
\text { Score }\end{array}$ & $\begin{array}{l}\text { Maximum } \\
\text { Score }\end{array}$ & Mean & Std. Error & Std. Dev. \\
\hline Academic qualification & 10.00 & 6.00 & 16.00 & 11.5732 & 0.18062 & 2.31310 \\
Social approval & 44.00 & 7.00 & 51.00 & 11.6524 & 0.29340 & 3.75736 \\
Physical appearance & 12.00 & 4.00 & 16.00 & 11.2805 & 0.22247 & 2.84906 \\
Close friendship & 11.00 & 5.00 & 16.00 & 11.7744 & 0.19444 & 2.49004 \\
Romantic relationship & 12.00 & 4.00 & 16.00 & 9.9573 & 0.16935 & 2.16880 \\
Professional competence & 11.00 & 4.00 & 15.00 & 11.1037 & 0.16011 & 2.05034 \\
Creativity & 12.00 & 4.00 & 16.00 & 10.6463 & 0.16811 & 2.15288 \\
Athletic compatibility & 12.00 & 4.00 & 16.00 & 10.6402 & 0.16947 & 2.17032 \\
Parents relationship & 11.00 & 5.00 & 16.00 & 12.1585 & 0.19874 & 2.54515 \\
Humor & 9.00 & 7.00 & 16.00 & 11.2378 & 0.21308 & 2.72877 \\
Moral standards & 12.00 & 4.00 & 16.00 & 13.0732 & 0.22894 & 2.93187 \\
Mental ability & 12.00 & 4.00 & 16.00 & 11.0488 & 0.16678 & 2.13589 \\
Holistic eigenvalues & 16.00 & 8.00 & 24.00 & 15.1646 & 0.20290 & 2.59844 \\
Self-esteem & 95.00 & 105.00 & 200.00 & 150.6918 & 1.39811 & 16.89340 \\
Subjective well-being & 76.00 & 70.00 & 146.00 & 111.0822 & 0.95395 & 11.52659 \\
Body image & 93.00 & 92.00 & 185.00 & 144.3973 & 1.73435 & 20.95627 \\
\hline
\end{tabular}

\section{The Results of Measurement Model}

Confirmatory factor analysis results used in the research are included in Table 3.

Table 3

Fit Indices and Reliability

\begin{tabular}{llllllc}
\hline \multirow{2}{*}{ Scales } & \multicolumn{2}{c}{ Subjective Well-Being } & & Self Esteem & \multicolumn{2}{c}{ Perception of Self-Image } \\
\cline { 2 - 7 } & First & Final & First & Final & First & Final \\
\hline Number of Items & 37 & 25 & 54 & 32 & 40 & 15 \\
$X^{2} / s d$ & 2.64 & 1.30 & 11.37 & 1.83 & 2.97 & 1.70 \\
RMSEA & 0.10 & 0.04 & 0.18 & 0.07 & 0.11 & 0.06 \\
SRMR & 0.09 & 0.06 & 0.15 & 0.07 & 0.09 & 0.05 \\
GFI & 0.64 & 0.85 & 0.37 & 0.80 & 0.60 & 0.90 \\
NFI & 0.82 & 0.90 & 0.87 & 0.94 & 0.84 & 0.95 \\
NNFI & 0.89 & 0.96 & 0.87 & 0.96 & 0.88 & 0.97 \\
CFI & 0.90 & 0.96 & 0.88 & 0.97 & 0.89 & 0.98 \\
Cronbach Alpha & 0.92 & 0.89 & 0.97 & 0.96 & 0.93 & 0.90 \\
Item Total Correlation & $0.24 / 0.61$ & $0.32 / 0.60$ & $0.50 / 0.68$ & $0.48 / 0.71$ & $0.21 / 0.67$ & $0.47 / 0.70$ \\
(Min./Max.) & & & & &
\end{tabular}


As seen in Table 3, it was determined that results of confirmatory factor analysis are on acceptable level with model data fit indices belonging to the scales; it was found out that Cronbach's alpha values of scales were 0.89-0.96 and 0.90 respectively, and article total correlations were over 0.20 .

\section{Findings Related to Hypotheses of the Research}

Table 4

Fit Indices of Structural Equation Model

\begin{tabular}{llc}
\hline & \multicolumn{2}{c}{ Result } \\
\cline { 2 - 3 } & First & Final \\
\hline$X^{2} / s d$ & 2.82 & 1.70 \\
RMSEA & 0.11 & 0.06 \\
SRMR & 0.09 & 0.08 \\
GFI & 0.67 & 0.78 \\
NFI & 0.87 & 0.90 \\
NNFI & 0.91 & 0.95 \\
CFI & 0.92 & 0.95 \\
\hline
\end{tabular}

As can be seen in Table 4, fit indices of structural equation model are generally acceptable and at a better level.

The aim of this study is to determine impact of adolescents' self-esteem and body image on subjective well-being. Independent variables of the study are body image perception and self-esteem, and dependent variable is subjective well-being.

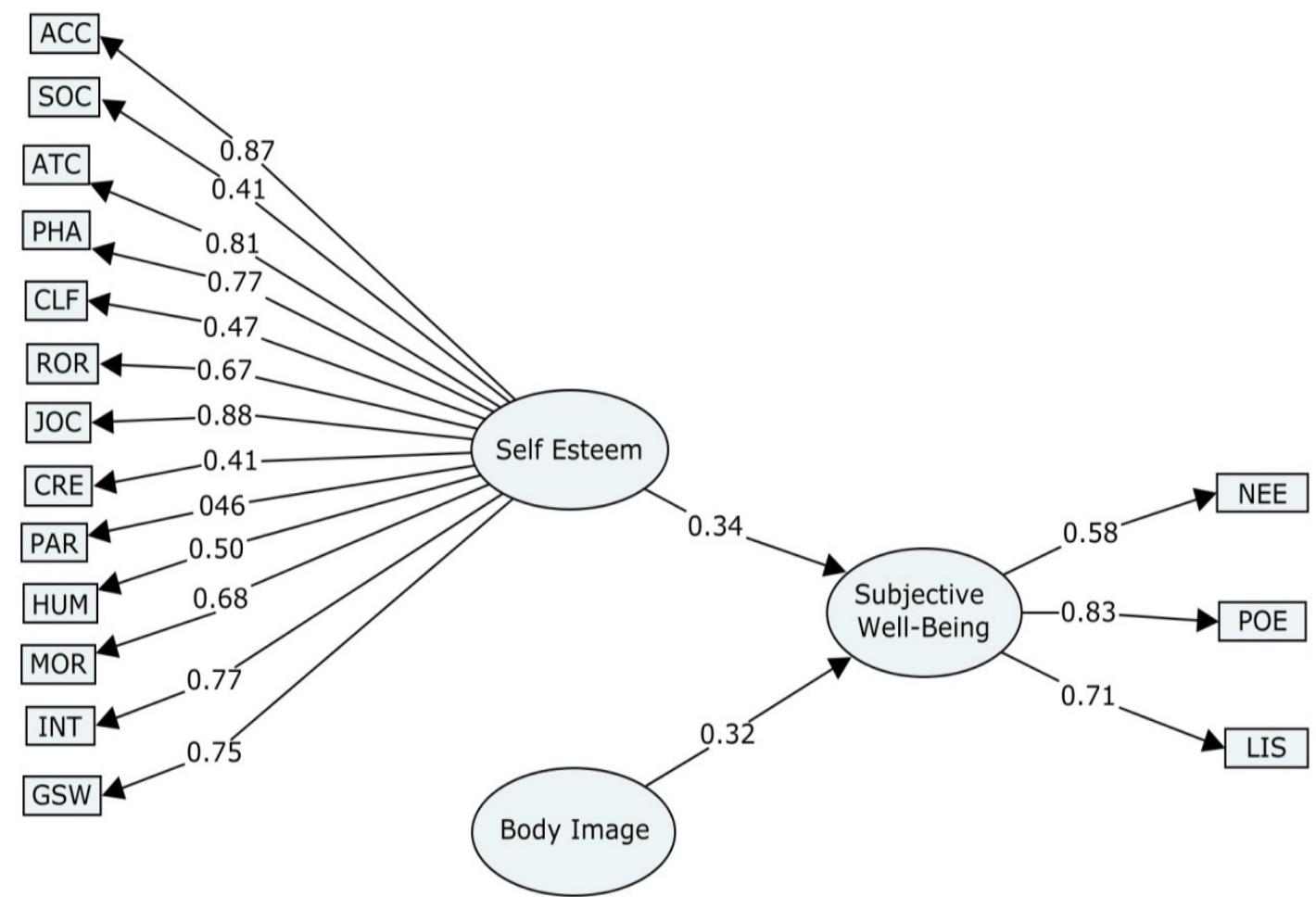

Figure 2. Structural Equation Model, Chi-Square $=721.65, d f=423, P$-value: 0.00000, RMSEA $=0.066$. (Abbreviations: ACC-Academic Ability, SOC-Social Competence, ATC-Athletic Competence, PHA-Physical Appearance, CLF-Close Friendship, ROR-Romantic Appeal, JOC-Job Competence, CRE-Creativity, PAR-Relationship with Parents, HUM-Humor, MOR-Morality, INT-Intellectual, GSW-Global Self-Worth). 
Table 5

Path Analysis Results

\begin{tabular}{lllllll}
\hline & & & & $\beta$ & $t$ & $R^{2}$ \\
\hline$H 1$ & Self-esteem & $\rightarrow$ & Subjective Well-Being & 0.34 & $3.54^{* *}$ & \multirow{2}{*}{0.28} \\
$H 2$ & Body-image perception & $\rightarrow$ & Subjective Well-Being & 0.32 & $3.34^{* *}$ & \\
\hline
\end{tabular}

Note. ${ }^{* *} p<0.01$.

Analyzing the structural equality models given in Table 5, following results relating to hypotheses are obtained:

H1 Acceptance: Self-esteem variable has a significant effect on the Subjective Well-Being $(\beta=0.34 ; t=$ $3.54 ; p<0.01)$.

H2 Acceptance: Body-image perception variable has a significant effect on the Subjective Well-Being $(\beta=$ $0.32, t=3.34, p<0.01)$.

H3 Acceptance: in the model, self-esteem and body image have positive and significant effect on the subjective well-being. These results demonstrate that self-esteem and body image perception affects the sense of subjective well-being positively. Both variables explain $28 \%$ of the change in subjective well-being feeling.

\section{The Other Findings Are Whether Differences According to Gender Adolescents' Self-esteem, Body Image, and Subjective Well-Being}

Independent Samples Test. As seen in Table 6, there are significant differences according to gender adolescents' self-esteem and body image, but there are not significant differences according to gender their subjective well-being.

Table 6

Independent Samples Test

\begin{tabular}{|c|c|c|c|c|c|c|c|c|c|}
\hline & \multicolumn{4}{|c|}{$\begin{array}{l}\text { Levene's Test } \\
\text { for Equality of } \\
\text { Variances } \\
\end{array}$} & \multicolumn{3}{|c|}{$t$-test for Equality of Means } & & \\
\hline & \multirow[t]{2}{*}{$F$} & \multirow[t]{2}{*}{ Sig. } & \multirow[t]{2}{*}{$t$} & \multirow[t]{2}{*}{$d f$} & \multirow[t]{2}{*}{$\begin{array}{l}\text { Sig. } \\
\text { 2-tailed }\end{array}$} & \multirow[t]{2}{*}{$\begin{array}{l}\text { Mean } \\
\text { Difference }\end{array}$} & \multirow[t]{2}{*}{$\begin{array}{l}\text { Std. } \\
\text { Error }\end{array}$} & \multicolumn{2}{|c|}{$\begin{array}{l}95 \% \text { Confidence } \\
\text { Interval of the } \\
\text { Difference }\end{array}$} \\
\hline & & & & & & & & Lower & Upper \\
\hline Body Image & 0.149 & 0.285 & 13.302 & 162 & 0.000 & 30.59 & 2.30 & 26.055 & 35.139 \\
\hline $\begin{array}{l}\text { Equal variances assumed } \\
\text { Equal variances not assumed }\end{array}$ & & & 13.302 & 162 & 0.000 & 30.59 & 2.300 & 26.055 & 35.139 \\
\hline Subjective Well-Being & 0.243 & 0.623 & 1.620 & 162 & 0.107 & 2.926 & 1.807 & -0.64179 & 6.49545 \\
\hline $\begin{array}{l}\text { Equal variances assumed } \\
\text { Equal variances not assumed }\end{array}$ & & & 1.620 & 160 & 0.107 & 2.926 & 1.807 & -0.64217 & 6.49583 \\
\hline Self Esteem & 0.448 & 0.504 & 2.358 & 162 & 0.020 & 6.207 & 2.632 & 1.008 & 11.406 \\
\hline $\begin{array}{l}\text { Equal variances assumed } \\
\text { Equal variances not assumed }\end{array}$ & & & 2.358 & 158 & 0.020 & 6.207 & 2.632 & 1.006 & 11.407 \\
\hline
\end{tabular}

\section{Discussion}

In this research, theoretical model developed relating to impact of adolescents' self-esteem and body image on subjective well-being has been tested and hypotheses establishing the objective of research have been verified. Accordingly, self-esteem and body image variables together have a significant impact on adolescents' subjective well-being. 


\section{Adolescents' Self-Esteem and Subjective Well-Being}

Analyzing the research findings under the light of related literature, high level of self-esteem was found to be associated with high subjective well-being (Trzesniewski, Donnellan, \& Robins, 2003). On the other hand, low level of self-esteem was found to be associated with several adverse events (Donnellan et al., 2005). For example, with regard to depression, anxiety and unconformity (Leary et al., 1995); it is emphasized that individuals with lower self-esteem are more sensitive to social cues compared to those with higher level of self-esteem (Korkut, 2004). While individuals with low self-esteem tend to value their abilities and suffer from denial of success frequently and experience difficulty in setting goals and solving problems (Plummer, 2005); among these adolescents, eating disorders, substance abuse, depressive mood, dissatisfaction with life, failure in satisfaction from life and deterioration in general well state and suicidal tendencies are more frequent (Spangler, 2002). In addition, it has been revealed that low self-esteem is associated with risk behaviors (Meggert, 2004); aggression, irresponsible sexual behaviors, becoming member of the deviant groups (Leary et al., 1995); substance abuse (Byrne, 2001); depressed mood, dissatisfaction with life and low level of general well-being (Dekovic, 1999); suicidality (Capuzzi \& Gross, 2000). In this context, while Leary (1999) discusses a number of psychological benefit of high self-esteem; that increasing low self-esteem value reveals terminal changes in human behaviors and increases psychological well-being. Therefore, increasing protective factors of studies towards improving self-esteem of children, young and adults in schools, families and other institutions is important from the point of showing its affect in protecting and improving mental health.

\section{Adolescents' Body Image and Subjective Well-Being}

Another finding of the research is that adolescents' body image affects subjective well-being positively and it is in parallel with many other research results. In these studies, relationship between body image and subjective well-being is emphasized (Diener et al., 1999; Donaghue, 2009; Tuzgöl-Dost, 2006). It is also stated that body image which is very important for adolescence at the same time contributes to development of adolescents' positive subjective well-being feelings (Oktan \& Şahin, 2010); and there is significant relationship with physical attractiveness (Diener \& Diener, 1995); feeling appreciation from body (Donaghue, 2009) and subjective well-being. In this regard, Tuzgöl-Dost (2006) has found out that there is a significant relationship between students' satisfaction from physical appearance and their subjective well-being. Besides, a distorted body image is associated with eating disorders, anorexia and bulimia nervosa (Wright, 1996).

Today, it is emphasized that especially among adolescents and young adults, dissatisfaction from body image is increasingly widespread (Verplanken \& Velsvik, 2008); also it is emphasized that perfect female and male models offerred to individuals with the concept of physical attractiveness contributes to establishment of a distorted body image, also brings along various unhealthy behaviors (Oktan \& Şahin, 2010). Similarly, it can be interpreted as a risk for adolescents that girls with low self-esteem tend to have negative body perception with regard to excessive dieting (Akın et al., 1992; Lyddon \& Slaton, 2002).

Adolescence is a period of time when the need for acceptance and approval is seen frequently. Physically and academically attractive adolescents seem to be more popular (Steinberg, 2007). Besides, body perception among adolescents is highly associated with their definitions about adolescents during transition period to adolescence; directing adolescents' attention toward its body can be clearly identified in the relationship between adolescents' body image and subjective well-being. On the other hand among adolescents, preventing eating disorders and increasing body perception will contribute to increase self-esteem and this situation may 
be interpreted in a way that relationship between self-esteem and body image can be evaluated from the point of subjective well-being (McVey, Davis, Tweed, \& Shaw, 2004). This situation means increasing adolescents' self-esteem and developing more realistic and positive attitude regarding their bodies and conducting studies towards accepting their bodies will also support adolescents' well-being.

\section{The Comparison as Gender}

Gender and Body Image. While girls' body image was more negative than those of boys, but their self-esteem was found higher, and their subjective well-being levels did not vary. This finding is considered important in terms of understanding the role of gender in adolescent researches. In this respect, each of research variables are discussed respectively as for its relationship with gender under the light of related literature. First of all, it was observed that girls' body image is more negative compared to that of males, and that girls are less satisfied with their bodies. This conclusion is also supported by other research (Jones, Bennett, Olmsted, Lawson, \& Rodin, 2001). As emphasized in the study, traditional mold judgments imposed on both genders socially cast different roles on the male and the woman. Accordingly, while males are expected to be more athletic, free, extrovert and effective compared to women; expectations from girls differ more in this sense (Freedman, Sears, \& Carlsmith, 1981). This situation makes more sense about the basic impact of gender in body image. Kundakc1 (2005) in his study, has found out that girl achieved higher score averages from Body Image Scale compared to boys; and that girls admired their bodies less than boys. In this case, while girls are expected to obey physical appearance considered as ideal based on their social roles; girls may have to focus on ideas related to their bodies more. It has seen observed that girls showed more interest in positive-negative thoughts about physical appearances expected from them.

Today, while the importance attached on physical appearance is mostly transmitted to individuals through mass media, a common admiration is expected to be established. Femininity and self-value are defined according to the ratio of body (Bulik, 2002). Epecially in the Western civilization, the concept of beauty is associated with the matching of an individual's weight and body shape with the form qualified as ideal (Jones et al., 2001; Levine \& Smolak, 1992). In this respect, the eating disorders being observed more frequent among girls show the fact that girls are under greater risk regarding the body image. For example, among girls attending high school, the ratio of those applying strategies towards losing weight was determined as $70 \%$, unusual and harmful methods were observed among these strategies (Steiner et al., 2003). Adolescence is considered not only as a period when physical changes come into prominence and body image gains importance, but as it is considered that perceptions related to physical appearance are important determinant of self-esteem.

Gender and Self-Esteem. While the another finding of this survey stating that girls' self-esteem are higher than that of boys is supported by some research results (Govender \& Moodley, 2004); in some studies, it has been determined that self-esteem scores do not vary by gender (Çevik-Büyükşahin \& Atıcı, 2007; Balat \& Akman, 2004). On the other hand, many factors may be effective in obtaining different results in the relationship between gender and self-esteem. For example, while many factos such as culture, selected measuring tools, selected sample and research conditions, etc., may be effective, other variables may be considered as effective in this relationship.

Gender and Subjective Well-Being. Other finding related to gender is that subjective well-being does not vary significantly in terms of gender. This finding supports findings included in the literature. In the literature, 
demographical variables are considered as a factor affecting the subjective well-being (Eryllmaz, 2009; Eryılmaz \& Aypay, 2011). Vast majority of researches applied on individuals from Western societies also revealed that gender did not have a significant effect on individuals' subjective well-being (Fujita, 1991). This situation can be associated with the finding that demographical characteristics affect subjective well-being up to the rate of $10 \%$ (Eryllmaz, 2010). In studies in which gender is associated with subjective well-being, different results have been observed (Acock \& Hurlbert, 1993). According to this finding, it is considered that gender may have direct effect on adolescents' subjective well-being; posing different roles on girls and boys in societies may be indirectly associated with subjective well-being.

Adolescence is a period of time consisting of biological, psychological, social and economic transition periods, in which children prepare for roles of adulthood, which contains a move from immaturity of childhood towards the maturity of adulthood, and where there are rapid growth, development and preparation for the future (Steinberg, 2007). At the same time, adoselence is a period in which growth and development in various physiological, social, psychological and sexual fields are experienced (Allen et al., 2002). While these experienced changes contribute to development of adolescents, in the same time, they may negatively influence adolescents' subjective well-being (Mcknight, Huebner, \& Suldo, 2002). That's why adolescents must fulfill many developmental tasks such as coping with and adapting to the changes during this period healthily, establishing an identity, gaining social and emotional competence in their future job. During this process, high level of subjective well-being may contribute to adolescents very much.

\section{Study Limitations and Future Directions}

It is necessary to mention some of the limitations of the research. Firstly, it can be interpreted as a limitation that the research is conducted with adolescents attending the first grade who are at the final stage of adolescence when body perception is substantially acquired. Therefore, it is possible to conduct future studies with younger adolescent groups with comparisons. Another limitation of the research is that participants is mainly Turkish, and it is considered another limitation for generalization of the findings that this study does not consider whether communitarian culture in Turkish culture has any effects on adolescents' well-being with comparison among various cultural structures.

In this direction, we can offer some proposals. Especially in psychological counseling and guidance' studies focus on adolescents' subjective well-being and increasing subjective well-being can be made by projects. At the same time; psychoeducation programs can be implemented towards healthy way of coping with intense changes emerging with the start of adolescence period, establishment of positive body perception and developing self-esteem. In addition, one must not ignore the findings regarding gender. In this respect, considering the fact that girls are under risk in terms of body image and self-esteem, school-based programs to be developed may target increasing self-respect and improving body image starting from changes that girls experience during adolescence. Furthermore, in the future, the studies could be done larger groups of adolescents by variety of socio-economic backgrounds and different cultures.

\section{Conclusion}

In this research, theoretical model developed relating to impact of adolescents' self-esteem and body image on subjective well-being has been tested and hypotheses establishing the objective of research have been verified. Accordingly, self-esteem and body image variables together have a significant impact on adolescents' 
subjective well-being. Adolescent well-being are important, as it leads to a hopeful adult. Entry into adolescence leads to less direct supervision and control by adults, more involvement with peers, participation in a wider and generally less nurturing school situation and movement within a wider geographical and social environment. The process of building good character among adolescents and ultimately enhancing their subjective well-being is complex. The goal of positive youth development is to build and strengthen resources that enable adolescents to grow and flourish throughout life. It is, after all, these young individuals who hold the future in their hands. They are the leaders of the future and if their levels of well-being are high, they can function at a higher optimal level and all of society can benefit from that (Diener \& Diener, 1995; Park, 2004).

Today, rapid economic and social changes bring about great risks in terms of adolescents' development. In this respect, protecting and developing adolescents' healthiness status, and preventing problems in this sense have become more and more important. Subjective well being, therefore, may be indicative adolescents' healthy development in terms of all aspects; in addition to fields such as mental health and education, with effective social policies, many adolescents can be engaged in healthy compromising and can reduce their problem-risky behavior. It is said that more attention is needed to discover the significant factors that influence subjective well-being of adolescents.

\section{References}

Acock, A. C., \& Hurlbert, J. S. (1993). Social networks, marital status, and well-being. Social Networks, 15(3), 309-334.

Adams, J. F. (1980). Understanding adolescence (4th ed.). Boston: Allyn \& Bacon Inc..

Akın, T., Baykara, A., Miral, S., \& Özakbaş, S. (1992). Youth body image and self-esteem relations' child and adolescent (pp. 418-424). Psychiatry Days Congress' Book, Izmir Medical Bookstore.

Allen, J. P., Hauser, S. T., O’Connor, T. G., \& Bell, K. L. (2002). Prediction of peer-rated adult hostility from autonomy struggles in adolescent-family interactions. Development and Psychopathology, 14, 123-137.

Balat, G., \& Akman, B. (2004). To investigation of self esteem levels of high school students of different socio-economic levels . Firat University Journal of Social Sciences, 14(2), 175-183.

Bar-On, R. (1998). The development of an operational concept of psychological wellbeing (Unpublished doctoral dissertation, Rhodes University, South Africa).

Bayram, N. (2010). Structural equation modeling in. Bursa: Ezgi Publishing.

Bulik, C. M. (2002). Eating disorder in adolescents and young adults. Child and Adolescent Psychiatric Clinics of North America, 17(2), 201-218.

Byrne, P. (2001). Psychiatric stigma. British Journal of Psychiatry, 178, 281-284.

Canpolat, B. I., Örsel, S., Akdemir, A., \& Özbay, M. H. (2003). Self-perception of body image in adolescents and the role of body mass index. 3P Journal, 11, 143-154.

Capuzzi, D., \& Gross, D. (2000). "I don't want to live”: The adolescent at risk for suicidal behavior. In D. Capuzzi, \& D. Gross (Eds.), Youth at risk: A prevention resource for counselors, teachers and parents (3rd ed., pp. 319-352). Alexandria, V.A.: American Counseling Association.

Chen, S., Boucher, H. C., \& Tapias, M. P. (2006).The relational self-revealed: Integrative conceptualization and implications for interpersonal life. Psychological Bulletin, 132, 151-179.

Collins, W. A., \& Steinberg, L. (2006). Adolescence. In W. Damon, R. M. Lerner, \& N. Eisenberg (Eds.), Handbook of child psychology (Vol. 3, Social, emotional, and personality development 6, pp. 1003-1067). New York: Wiley.

Columbo, S. A. (1986). General well-being in adolescents: Its nature and measurement (Doctoral dissertation, Saint Louis University).

Çelen, N. (2007). Conversion process: Adolescence and young adulthood. Istanbul: Papatya Publishing.

Çevik-Büyükşahin, G., \& Atıcı, M. (2009). To examining high school 3 grade students self-esteem and some variables. International Journal of Human Sciences, 6(1), 339-352.

Çokluk, Ö., Şekercioğlu, G., \& Büyüköztürk, Ş. (2010). Multivariate statistics for the social sciences. Ankara: Pegem Publications. 
Dekovic, M. (1999). Risk and protective factors in the development of problem behavior during adolescence. Journal of Youth and Adolescence, 28, 667-685.

Diener, E. (1984). Subjective well-being. Psychological Bulletin, 95, 542-575.

Diener, E., Suh, E. M., Lucas, R. E., \& Smith, H. L. (1999). Subjective well- being: Three decades of progress. Psychological Bulletin, 125(2), 276-302.

Deiner, E., \& Diener, M. (1995).Cross-cultural correlates of life satisfaction and self-esteem. Journal of Personality and Social Psychology, 68, 653-663.

Diener, E., \& Seligman, M. E. P. (2002). Very happy people. Psychological Science, 13, 80-83.

Donaghue, N. (2009). Body satisfaction, sexual self-schemas and subjective well-being in women. Body Image, 6, 37-42.

Donnellan, M. B., Trzesniewski, K. H., Robins, R. W., Moffit, T. E., \& Caspi, A. (2005). Low self-esteem is related to agression, antisocial behavior, and delinquency. Psychological Science, 16, 328-335.

Dönmez, A. (1985). Locus of control, self-esteem and three variables: Environmental size, age, family atmosphere. Education and Science, 10, 4-15.

Erikson, E. H. (1968). Identity: Youth and crisis. New York: W. W. Norton.

Eryılmaz, A. (2009). The mediating role of coping with strategies the between adolescent personality traits and subjective well-being (Unpublished Doctoral Dissertat, The Institute of Education Sciences, Ankara).

Eryılmaz, A. (2010). The scale of subjective well-being increasing strategies for adolescents. Turkish Psychological Counseling and Guidance Journal, IV( 33), 81-88.

Eryılmaz, A., \& Aypay, A. (2011). Investigation of relationship between adolescents' subjective well-being and identity status. Dicle Üniversity Journal of ZiyaGokalp Faculty of Education, 16, 167-179.

Fujita, F. (1991). An investigation of the relation between extroversion, neuroticism, positive affect, and negative affect (Master's Thesis, University of Illinois).

Freedman, J. L., Sears, D. O., \& Carlsmith, J. M. (1981). Social psychology (4th Ed., p. 686). Englewood Cliffs, N.J.: Prentice Hall.

Gerrig, P., \& Zimbardo, G. (2010). Psychology and life (19th Ed.). New Jersey: Pearson Education, Inc..

Gilman, R., \& Huebner, E. S. (2006). Characteristics of adolescents who report very high life satisfaction. Journal of Youth and Adolescence, 35(3), 311-319.

Govander, K., \& Moodley, K. (2004). Maternal support and adolescent self-esteem. Journal of Children and Poverty, 10(1), 37-52.

Guindon, M. H. (2002). Toward accountability in the use of the self-esteem construct. Journal of Counseling \& Development, Spring, 80, 204-214.

Harter, S. (1990). Developmental differences in the nature of self-representations: İmplications for the understanding, assessment and treatment of maladaptive behavior. Cognitive Therapy and Research, 14, 113-142.

Hovardaoğlu, S. (1992). Body Perception Scale: Psychiatry, Psychology. Journal of Psycho-pharmacology (3P). Tests Specific Issue.

Jones, J. M., Bennett, S., Olmsted, M. P., Lawson, M. L., \& Rodin, G. (2001). Disordered eating attitudes and behaviors in teenaged girls: A school-based study. CMAJ, 165, 547-552.

Jorgenson, R. S., \& Dusek, J. B. (1990). Adolescent adjustment and coping strategies. Journal of Personality, 58(3), 503-513.

Kaplan, L. (1995). Self-esteem is not our national wondern drug. The School Counselor, 42(5), 341-346.

Korkut, F. (2004). Prevention and wellness. Journal of Educational Research, 4(15), 79-87.

Kundakc1, A. H. (2005). The comparison eating attitudes of university students by self-perception, stress symptoms and body perception (Unpublished Master's Thesis, Social Sciences Institute of Ankara University).

Levine, M., \&, Smolak, L. (1992). Toward a model of the developmental psychopathology of eating disorders: The example of early adolescence. In J. H. Crowther, D. L. Tennenbaum, S. E. Hobfoll, \& M. A. P. Stevens (Eds.), The etiology of bulimia nervosa: The individual and familial context. Washington: Hemisphere.

Leary, M. R. (1999). The social and psychological importance of self-esteem. In R. M. Kowalski, \& M. R. Leary (Eds.), The social psychology of emotional and behavioral problems: Interfaces of social and clinical psychology (pp. 197-221). Washington, D.C.: American Psychological Association.

Leary, M. R., Tambor, E. S., Terdal, S. K., \& Downs, D. L. (1995). Selfesteem as an interpersonal monitor: The sociometer hypothesis. Journal of Personality and Social Psychology, 68, 518-530.

Lucas, R. E., Deiner, E., \& Suh, E. (1996). Discriminant validity of well-being measures. Journal of Personality and Social Psychology, 71, 616-628. 
Lyddon, W., \& Slaton, K. (2002). Promoting a healthy body image among adolescent women. In C. Juntunen, \& D. Atkinson (Eds.), Counseling across the lifespan: Prevention and treatment (pp. 159-183). Thousand Oaks, C.A.: SAGE Publications, Inc..

Lyubomirsky, S., Tkach, C., \& Dimatteo, M. (2006). What are the differences between happiness and self-esteem? Social Indicators Research, 78, 363-404.

Mcknight, C. G., Huebner, E. S., \& Suldo, S. (2002). Relationships among stressful life events, temperament, problem behaviour, and global life satisfaction in adolescents. Psychology in the Schools, 39(6), 677-687.

McVey, G., Davis, R., Tweed, S., \& Shaw, B. F. (2004). Evaluation of a school-based program designed to improve body image satisfaction, global self-esteem, and eating attitudes and behaviors: A replication study. International Journal of Eating Disorders, 36(1), 1-11.

Meggert, S. S. (2004). Who cares what I think: Problems of low self-esteem. In D. Capuzzi, \& D. R. Gross (Eds.), Youth at risk: A prevention resource for counselors, teachers, andparents (4th ed., pp. 93-115). Alexandria, V.A.: American Counseling Association.

Myers, J. E. (2001). Well workbook. Los Angelas: Mind Garden Publisher.

Myers, D., \& Deiner, E. (1995). Who is happy. American Psychological Society, 6(1), 1-19.

Oktan, V., \& Şahin, M. (2010). Examining the relationship between body image and self-esteem in adolescents girls. International Journal of Human Sciences, 7(2).

Özen, Ö. (2005). Levels of subjective well-being of adolescents (Master Thesis, Hacettepe University, Institute of Social Sciences. Ankara).

Özoglu, S. (1975). Self-concept counseling. Ankara University Faculty of Educational Sciences Journal, 8, 93-112.

Park, N. (2004). The role of subjective well-being in positive youth development. The Annals of the American Academy of Political and Social Science, 591, 25-39.

Pesa, J. A., Syre, T. R., \& Jones, E. (2000). Psychosocial differences associated with body weight among female adolescents: The importance of body image. J. Adolesc Health, 26, 330-337.

Plummer, D. (2005). Helping adolescents and adults to build self esteem. London: Jessica Kingsley.

Rask, K., Astedt-Kurki, P., \& Laippala, P. (2002). Adolescent subjective wellbeing and realized values. Journal of Advanced Nursing, 38(3), 254-263.

Reber, A. S., \& Reber E. S. (2001). The Penguin dictionary of psychology (3rd ed.). London: Penguin.

Ryan, M. R., \& Deci, E. L. (2000). Self-determination theory and the facilitation of intrinsic motivation, social development, and well-being. American Psychologist, 55(1), 68-78.

Schaufeli, W. B., Martínez, I., Marques-Pinto, A., Salanova, M., \& Bakker, A. B. (2002). Burnout and engagement in university students: A cross national study. Journal of Cross-Cultural Psychology, 33, 464-481.

Schwarz, N., \& Clore, G. L. (1983). Mood, misattribution, and judgements of well-being: Informative and directive functions of affective states. Jour of Personality and Social Psychology, 45(3), 513-523.

Spangler, D. L. (2002). Testing the cognitive model of eating disorders: The role of dysfunctional beliefs about appearance. Behavior Therapy, 33, 87-105.

Steinberg, L. (2007). Adolescence (Translated by F. Çok ). Ankara: Imge Publishing.

Steiner, H., Kwan, W., Shaffer, T. G., Walker, S., Miller, S., Sagar, A., et al. (2003). Risk and protective factors for juvenile eating disorders. European Child \& Adolescent Psychiatry, 12, 38-46.

Swann, W. B. Chang-Schneider, C., \& McClarty, K. L. (2007). Do people's self-views matter? Self-concept and self-esteem in everyday life. American Psychologist, 62, 84-94.

Şahin, D., \& Güvenç, G. B. (1996). Adolescents' family perception and self-perception. Turkish Journal of Psychology, 38, 22-32.

Tong, Y., \& Song, S. (2004). Study on general self-efficacy and subjectıve well-being of low ses college students in a Chinese university. College Student Journal, 38(4), 637-644.

Trzesniewski, K. H., Donnellan, M. B., \& Robins, R. W. (2003). Stability of self-esteem across the life span. Journal of Personality and Social Psychology, 84, 205-220.

Tuzgöl-Dost, M. (2005). Development of Subjective well-being scale: Validity, reliability. Turkish Psychological Counseling and Guidance Journal, 3(23), 103-110.

Tuzgöl-Dost, M. (2006). Subjective well-being among university students. Hacettepe University Faculty of Education Journal, 31, 188-197. 
Walz, G. R. (1992). Enhancing self-esteem AACD individual-study program. In G. R. Walz, \& J. C. Bleuer (Eds.), Student self esteem: A vital element of school suvvess (pp. 35-49). Ann Arbor, Michigan: Counseling and Personnel Services, Inc..

Wells, E., \& Marwell, G. (1976). Self-esteem: Its conceptualization and measurement. Beverly Hills: Sage Publications, Inc..

Verplanken, B., \& Velsvik, R. (2008). Habitual negative body image thinking as psychological risk factor in adolescents. Body Image, 5(2), 133-140.

Visser, M., \& Routledge, L. (2007). Substance abuse and psychological wellbeing of South African adolescents. South African Journal of Psychology, 37(3), 595-615.

Witmer, J. M., \& Sweeney, T. J. (1992). A holistic model for wellness and prevention over the life span. Journal of Counseling \& Development, 71, 140-147.

Wright, K. (1996). The secret and all-consuming obsessions: Anorexia and bulimia. In D. Capuzzi, \& D. R. Gross (Eds.), Youth at risk: A prevention resource for counselors, teachers, and parents (2nd ed., pp. 153-181). Alexandria, V.A.: American Counseling Association. 